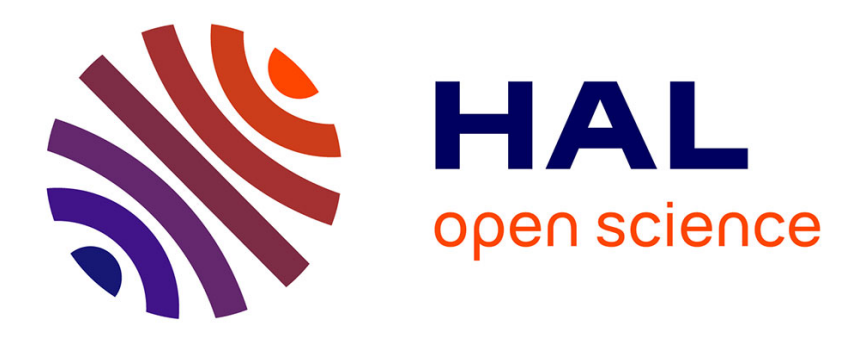

\title{
Statistical behaviour of dielectric discharges on satellites : a new experimental approach
}

\author{
J.P. Marque
}

\section{To cite this version:}

J.P. Marque. Statistical behaviour of dielectric discharges on satellites : a new experimental approach. Revue de Physique Appliquée, 1986, 21 (12), pp.817-824. 10.1051/rphysap:019860021012081700 . jpa-00245504

\section{HAL Id: jpa-00245504 https://hal.science/jpa-00245504}

Submitted on 1 Jan 1986

HAL is a multi-disciplinary open access archive for the deposit and dissemination of scientific research documents, whether they are published or not. The documents may come from teaching and research institutions in France or abroad, or from public or private research centers.
L'archive ouverte pluridisciplinaire HAL, est destinée au dépôt et à la diffusion de documents scientifiques de niveau recherche, publiés ou non, émanant des établissements d'enseignement et de recherche français ou étrangers, des laboratoires publics ou privés. 


\title{
Statistical behaviour of dielectric discharges on satellites : a new experimental approach $\left(^{+}\right)$
}

\author{
J. P. Marque
}

Office National d'Etudes et de Recherches Aérospatiales, BP 72, 92322 Châtillon Cedex, France

(Reçu le 17 janvier 1986, révisé le 10 juillet, accepté le 31 juillet 1986)

\begin{abstract}
Résumé. - L'irradiation sous vide par des électrons énergétiques de films de polymère conduit à l'apparition de décharges se propageant à la surface de ces matériaux. De telles décharges pourraient être à l'origine de perturbations radioélectriques observées sur les satellites géostationnaires en période d'orage magnétique. Ces décharges peuvent se déclencher sur un défaut ou à un bord du matériau ou être provoquées par la rupture diélectrique de l'échantillon. On observe une distribution statistique des valeurs du potentiel de déclenchement $V_{\mathrm{s}}$, qui peut être décrit par la loi de Weibull.

Les paramètres caractéristiques de la décharge (intensité du courant, vitesse de propagation...) présenteront alors un comportement identique ; celui-ci pourra être décrit par une loi semblable dans le cas de variations du paramètre en $\left(V_{\mathrm{s}}-V_{0}\right)^{\gamma}$. Nous analysons dans cet article les mesures de vitesse de propagation de décharges linéaires obtenues par Balmain et al. (1982). Nous montrons que la loi de Weibull rend compte de la distribution des valeurs de vitesse. Nous pourrons envisager l'expression suivante pour la vitesse de propagation, $W$ :
\end{abstract}

$$
W=\alpha\left(V_{\mathrm{s}}-V_{0}\right)^{\gamma}
$$

Une relation semblable a été établie à pression atmosphérique dans le cas des décharges de surface négative $(\gamma=1)$ et positive $(\gamma<1)$.

Une approche expérimentale basée sur la détermination des lois statistiques gouvernant les paramètres importants de ces décharges est proposée.

\begin{abstract}
Polymeric insulating layer may show propagating surface discharges when they are irradiated under vacuum with high energy electrons. Such discharges could create electromagnetic interferences on geosynchronous spacecraft during magnetic storms. These discharges can be triggered at a defect zone or at the edge of the sample or following the electrical breakdown of the material. The values of the onset potential $V_{\mathrm{s}}$, obey a statistical law which may be described by the Weibull distribution function. The characteristic parameters of the discharge (current intensity, velocity...) will present the same statistical behaviour.

The same distribution can be used to statistically describe it in the case of a power law function of the parameter with the potential. In this paper we have analysed the measurements of linear discharge propagation velocity obtained by Balmain et al. (1982) on different materials. We have shown that these values were distributed in accordance with a Weibull function. The following general expression may be set for the velocity of the discharge, $W$ :

$$
W=\alpha\left(V_{\mathrm{s}}-V_{0}\right)^{\gamma}
$$
\end{abstract}

Such a relationship had already been determined in the case of negative $(\gamma=1)$ or positive $(\gamma<1)$ surface discharges at atmospheric pressure in air.

An experimental approach is then proposed to evaluate the statistical laws governing the main parameters of the e-irradiated dielectric discharges.

\section{Introduction.}

During magnetic storm development, geosynchronous spacecraft are immersed in a high energy electron cloud - mainly in the range $5-50 \mathrm{keV}$.

In the first approximation, the satellite behaves as

$\left(^{+}\right)$Cet article a fait l'objet d'une communication à la Conférence Internationale sur la Foudre et l'Electricité Statique (Paris, 10-15 juin 1985). a plasma probe ; but as a composite structure of elements having different electrical properties (conductivity, secondary emission...), it will show large differential potential of a few $\mathrm{kV}$ between, for example, dielectric covers and the metal structure. Electric fields may be large enough to trigger $E S D\left(^{*}\right)$ and to create electronic disfunction due to electromagnetic interference. To reduce ground

(*) ESD : Electrostatic discharge. 
monitoring and increase reliability, we have to understand the physical properties of these discharges ; this means we have to solve the following problems :

1) forecasting the risks of discharges occurring on a satellite in a given environment ;

2) quantifying the level of the electromagnetic interference: that is determine the spatial and temporal evolution of the emitted current which is the perturbation source function.

This work can be divided into four main items (Fig. 1) concerning :

- the environment of the satellite,

- the electrical configuration of the satellite,

- the discharge parameters,

- the electromagnetic coupling.

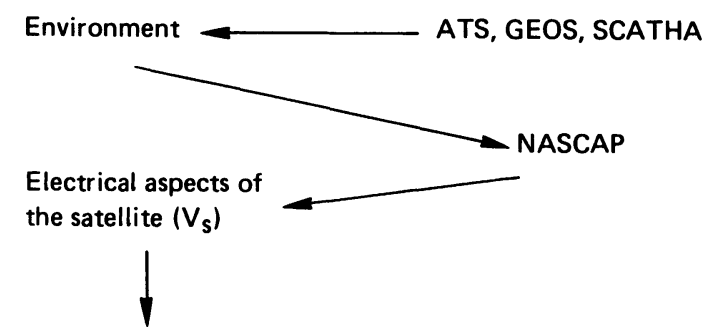

Probability and characteristic of discharges?

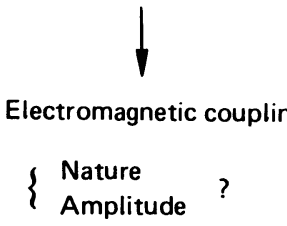

Fig. 1. - Simplified diagram of spacecraft charging problems.

Up to now, large amounts of data from scientific satellites, such as GEOS or SCATHA have given a sufficient knowledge of substorm periods and accurate models [1] can be used to describe them. As input data for the $N A S C A P$ code [2], for example, they can give a good description of the electrical behaviour of the spacecraft during charging processes. The first two phases may now be considered as nearly achieved.

Conversely, we are still far from having directly applicable data available in the case of the two last problems. For a given satellite structural configuration, various mechanisms may be assumed to provoke discharges.

The values of potential for which discharges occur on laboratory irradiated dielectric films are not always compatible with the values obtained from the NASCAP Program when it was used for processing the entire satellite's structure or those actually measured during SCATHA flight. Additional measu- rements have gradually been suggested and verified experimentally :

- discharges between conductors (metallic discharges),

- discharges specific to a configuration (solar arrays),

- discharges on dielectric films submitted to multienergy electron beam.

Therefore, we do not have a clear idea of either the relative frequency of occurrence for each type of discharge or of the risk increase with respect to the potential (or the beam energy) and the coupling mechanisms of the associated electromagnetic radiation. We are far from a parametric description of any type of discharge ; this is especially true for discharges occurring on dielectric coatings which is the subject of this paper. We think it is important that this discharge mechanism be understood. First protection against metallic discharges can be rather easily realized by careful metallization to the usual specifications for satellite construction. In addition, study of these discharges is an inevitable step towards the understanding of a more complex situation resulting in a better simulation of the geostationary environment (multivalent electron energy spectra, ions, etc.).

\section{Why a statistical approach ?}

Concerning this type of discharge, a too great variety and divergence are found in the litterature to now deduce any general and useful laws which could link the most important parameters (as those related to the current) to the surface potential (this last parameter being considered as representative of the stored energy).

One of the reasons being that these discharges are obtained under uniform irradiation conditions leading to tree-like discharges. These discharges are not reproducible and resulting signals are the convolution of all the contributing branches. This does not allow an analysis of what happens in each branch which is the fundamental process we have to understand before considering the very general case. However in the case of surface discharges at atmospheric pressure such relationships have been established between the current waveforms, the discharge velocities or the radiated fields and the potential of the support upon which the discharges propagate. This has been studied by Bondiou [3, 4] and Larigaldie [5] in the case of linear discharges which can be considered as elementary processes of branched discharges. Once the laws are established for this « fundamental brick », the development of the treelike discharge may be well approximated by using different computation techniques.

The discharges at atmospheric pressure exhibit some similarity with vacuum surface discharges first by their visual aspect (Fig. 2), but also by the practical situation in which they both occur: let's consider the general configuration of a dielectric 


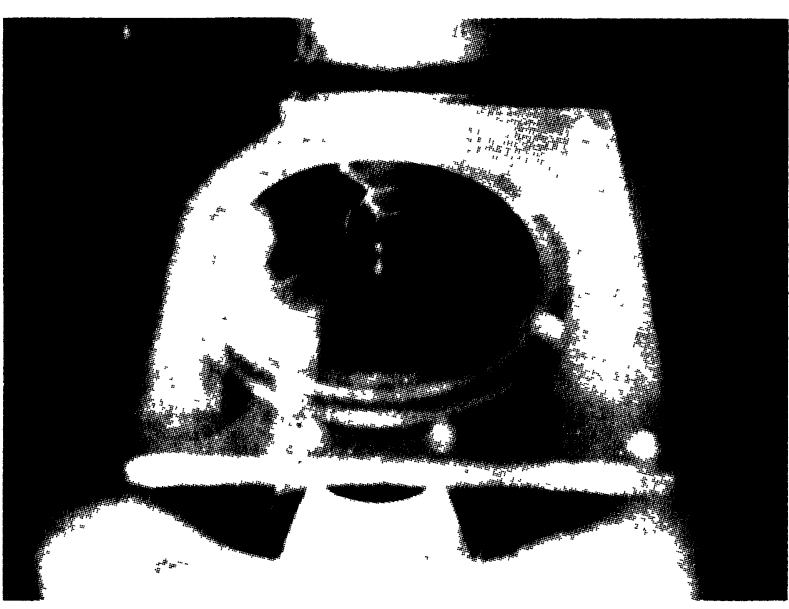

a)

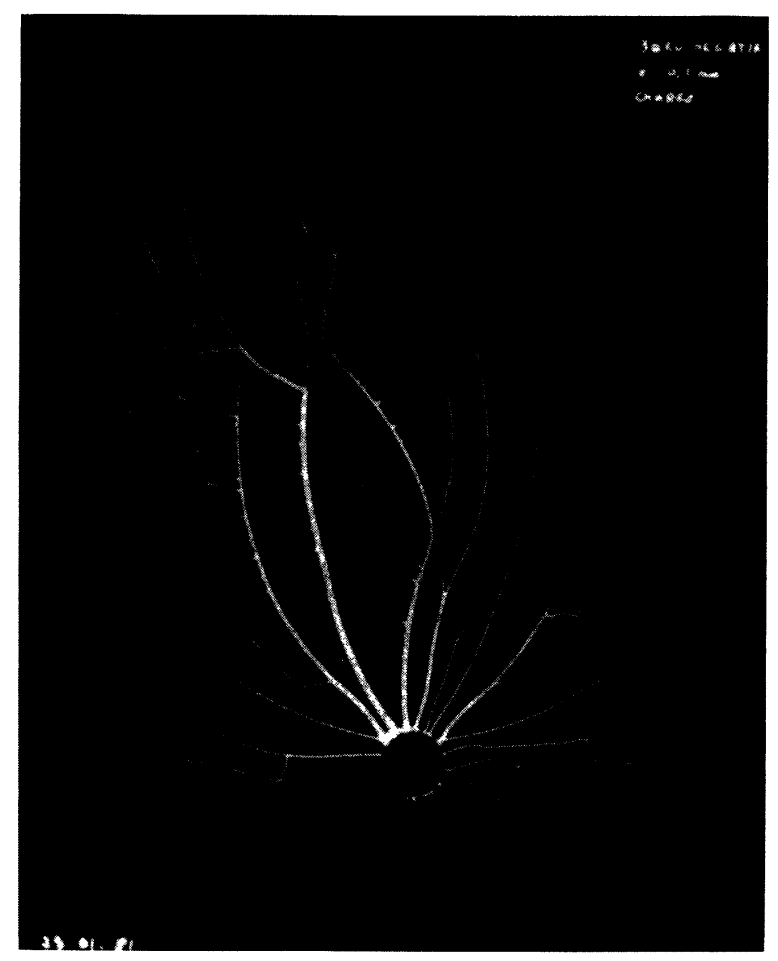

b)

Fig. 2. - Surface discharges ; (a) Vacuum discharge on eirradiated Teflon $(125 \mu \mathrm{m})$. The flashover discharge was triggered by dielectric breakdown of the material (scale 1/3) ; (b) Air discharge propagating on a photographic plate $(100 \mu \mathrm{m})$. The plate is previously charged by a $\mathrm{H}$.V. corona comb $\left[V_{\mathrm{s}}=30 \mathrm{kV}\right]$; the discharge is triggered by grounding a metallic electrode on the surface (scale 1/2) [5].

plate or film surrounded by its metal structure as represented in figure 3 . The only difference between air and vacuum discharges consists in the way charges are deposited: ions at the surface for air discharges, embedded electrons up to several microns under the surface for irradiated material in

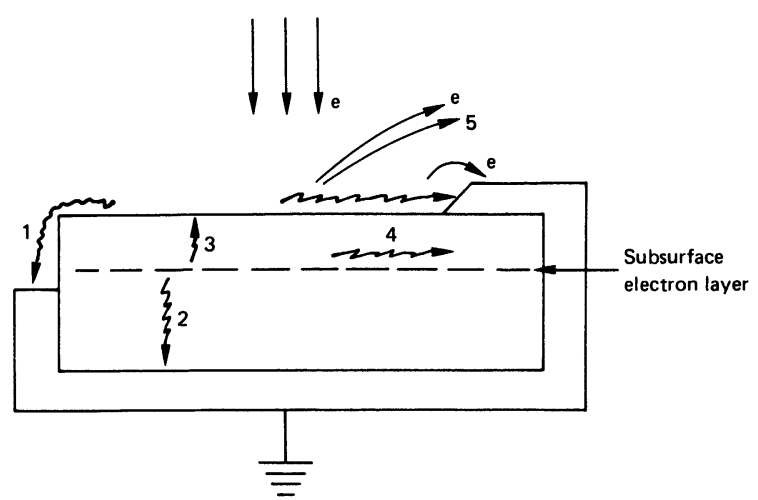

Fig. 3. - General configuration of discharge occurring (only processes 1 and 2 in air); 1 : junction breakdown (flashover), 2 : punch through (dielectric breakdown), 3 : punch through (dielectric breakdown), 4: subsurface discharge (dielectric breakdown), 5 : blowoff emission.

vacuum. The discharge will propagate in different media : air or dielectric or desorbed gas stimulated by electron irradiation.

Discharges may occur due to breakdown at the structure-dielectric junction or due to dielectric breakdown (that is to say breakdown in the volume of the material whatever the mechanism may be which may be different depending on charge nature).

At atmospheric pressure for each case, when air is involved in the triggering of the discharge (mainly junction breakdown) breakdown will occur for $a$ well-determined value, $V_{\mathrm{s}}$, of the surface potential which only depends upon the geometry. By plotting characteristic values of surface potential $V_{s}$, versus material thickness, we obtain horizontal straight line.

After initiation, the discharge will propagate only if this value $V_{\mathrm{s}}$ is higher than the Toepler threshold $V_{0}$, which is proportional to the square root of the thickness.

In figure 4 we plot different characteristic values of the potential versus the thickness of the material.

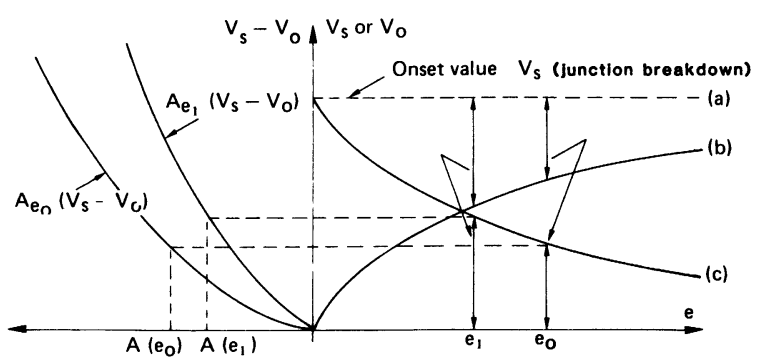

Fig. 4. - Parametric description of air discharges. (a) constant value of the onset potential for a given geometry: $V_{\mathrm{s}}$; (b) threshold curve : $V_{0} \propto\left(\frac{e}{\varepsilon_{\mathrm{R}}}\right)^{1 / 2}$; (c) driving potential $V_{\mathrm{s}}-V_{0}$. By varying the curve (a) for one value of the thickness $e_{0}$, we describe the development of the parameter $A$ as a function of the driving potential $A_{e_{0}}\left(V_{\mathrm{s}}-V_{0}\right)$. 
For one value $e_{0}$ of this thickness, we have one value of the driving potential $V_{\mathrm{s}}-V_{0}$ and also one value of a particular studied parameter $A$. By varying the surface potential value it is possible to describe the evolution of this parameter $A$ with the driving potential and to obtain the curve $A\left(V_{\mathrm{s}}-V_{0}\right)$.

Experimental configurations can be set up that yield different onset potential values: different parameters $A$ as the current intensity, the current risetime or the propagation velocity, etc... may be expressed as a simple function of the potential difference $V_{\mathrm{s}}-V_{0}$.

Figure 5 shows the relation concerning the current intensity at the velocity of the linear negative air

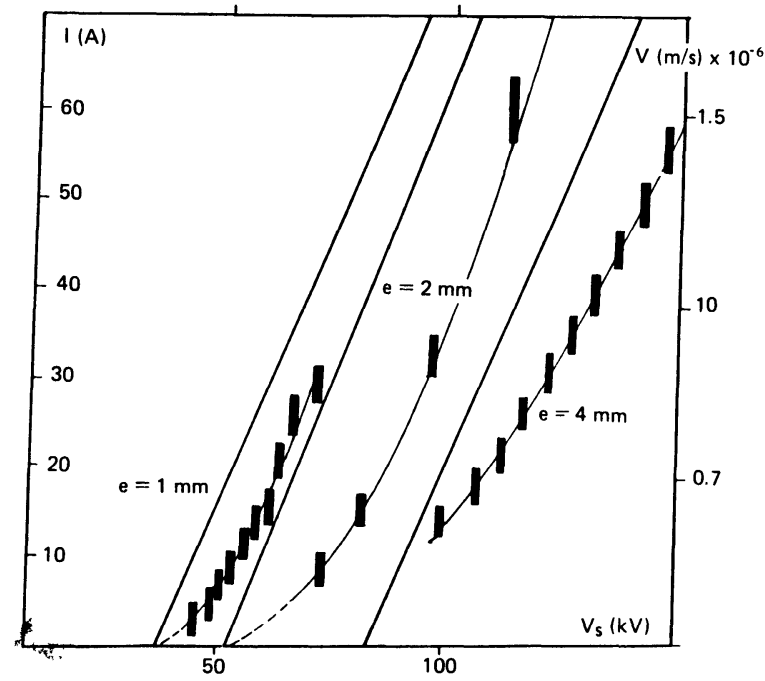

Fig. 5. - Current (I) and velocity relationship versus surface potential $V_{\mathrm{s}}$ in the case of linear surface discharge propagating on plexiglass plates of different thicknesses [4]: $e=1 \mathrm{~mm}, V_{0}=32 \mathrm{kV}-e=2 \mathrm{~mm}, V_{0}=$ $52.5 \mathrm{kV}-e=4 \mathrm{~mm}, V_{0}=84 \mathrm{kV}$.

discharge for a thick plate of $1 \mathrm{~mm}$ and more. The intensity is a quadratic function of the voltage :

$$
I=\beta V_{\mathrm{s}}\left(V_{\mathrm{s}}-V_{0}\right),
$$

and the velocity a linear one :

$$
v=\alpha\left(V_{\mathrm{s}}-V_{0}\right) \text {. }
$$

$V_{0}$ is the Toepler threshold value.

For thin films as $125 \mu \mathrm{m}$ Teflon, $V_{0}$ is about $17 \mathrm{kV}$; so for a surface voltage of $25 \mathrm{kV}$, the velocity could be around $3 \times 10^{5} \mathrm{~m} \mathrm{~s}^{-1}$.

We think that similar laws may exist for vacuum dielectric discharges and first for the simplest of them, the linear guided discharge. But, to establish this, it is necessary to resolve a statistical problem. Indeed, in the case of vacuum discharges, in both breakdown configuration (dielectric or junction), the material is involved.
We know that the electrical behaviour of polymers is greatly affected by defects : for example, this is why dielectric breakdown, is a statistical phenomenon. In a given condition of field and geometry we may only calculate the probability of breakdown occurring.

It is also the reason why vacuum discharges involving polymers are more complex to study than breakdown in air, the statistical behaviour being added to all the other aspects of propagation.

The discharge may appear for a voltage distribution independent of the thickness, or for an electric field distribution which leads to a voltage distribution proportional to the thickness ; this last case corresponds to the dielectric breakdown. The two cases are represented in figure $6 a$ and $b$, for which we have set $V_{0}=0$.

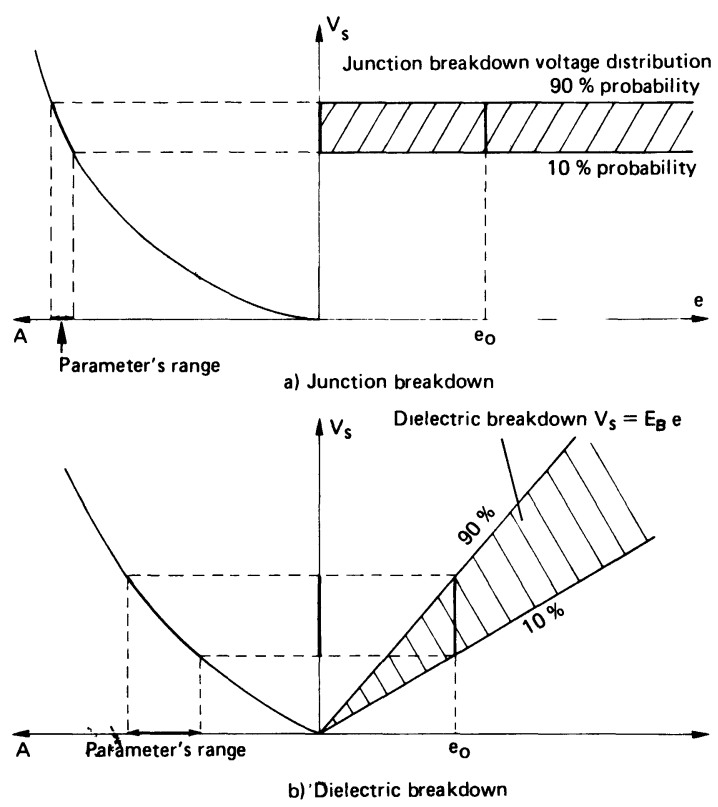

Fig. 6. - Effect on the measured value of the parameter $A$, of the statistical occurrence of the discharge. Onset potentiel can take any value in a range defined by low (i.e. $10 \%$ ) and high (i.e. $90 \%$ ) probability value. (a) Junction breakdown ; (b) dielectric breakdown.

For a given value of the thickness, $e_{0}$, we only have access to a possible range of the disrupting potential due to the statistical behaviour of the phenomena.

So, if in both these cases leading to the discharge the characteristic parameter (the electrical strength or the potential itself) obey a statistical law $P\left(E_{\mathrm{s}}\right)$ or $P\left(V_{\mathrm{s}}\right)$, we shall have a probabilistic appearance of the discharge.

Each parameter $A\left(V_{\mathrm{s}}\right)$ of interest will only be known through its own probability law $P_{A}\left(V_{\mathrm{s}}\right)$ or $P^{\prime}(A)$ (Fig. 6). The only way to access to a reliable parametric description of the discharge, which can be useful to spacecraft engineers, is to determine this law. 
We do not think that ESD's appear at random but rather that, for a given configuration, they follow a law of failure probability which is not Gaussian.

\section{Weibull distribution function.}

We know that the Weibull distribution function is often applied to the failure of material under electrical stresses.

The probability $P$ with which a random variable $X$ assumes values up to, but not exceeding a given value $x$ is a non decreasing function of $x$ :

$$
F(x)=P(X \leqslant x) .
$$

The definition of $F(x)$ is referred to as the failure cumulative distribution function.

Weibull distribution

$$
F(x) \begin{cases}1-\exp -\left(\frac{x-x_{0}}{x_{\mathrm{c}}-x_{0}}\right)^{\mathrm{b}} & x \geqslant x_{0} \\ 0 & x<x_{0}\end{cases}
$$

$x_{0}$ : lower limit of the random variable below which no failure can occur.

$x_{\mathrm{c}}$ : characteristic value at which $F\left(x=x_{\mathrm{c}}\right)=$ $1-1 / e$ that is $63.2 \%$ of the failures have occurred.
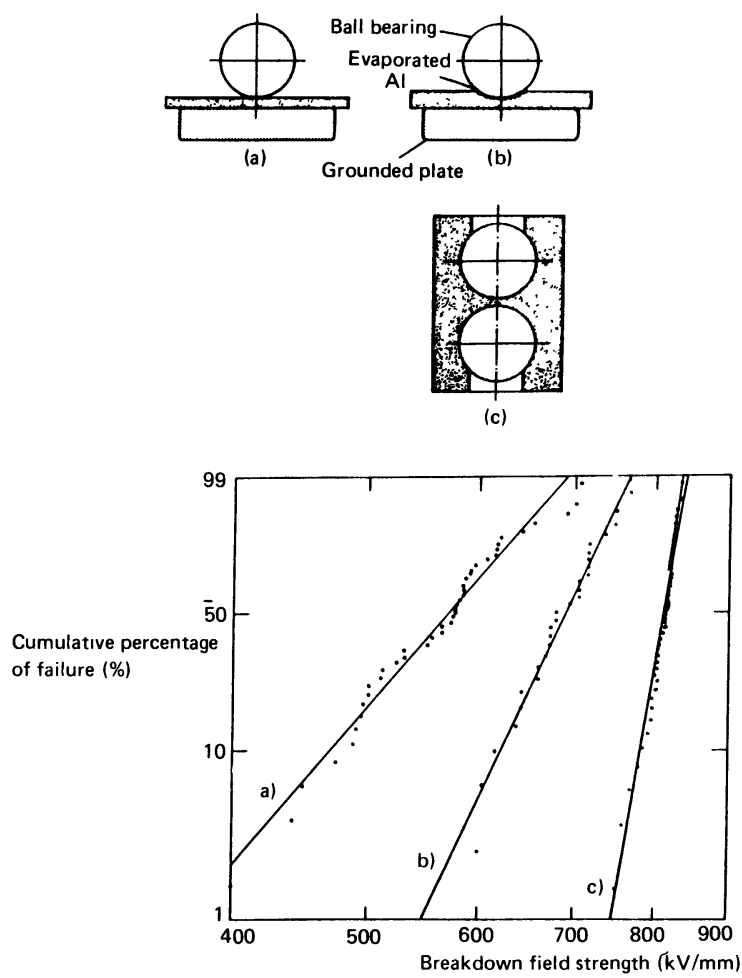

Fig. 7. - DC failure field strengths of L.D. polyethylene using various experimental geometries (from [7]). Common laboratories sample geometries for the determination of the electrical strength of polymers. (a) Film sample ; (b) recessed specimen ; (c) cylindrical specimen. Adapted from: Electrical Properties of polymers Ed. D. A. Seanor (1982).
Recently, Hill and Dissado [6], gave a possible physical explanation of this law and its parameters in terms of electric field fluctuations in the volume of the material.

Estimation of the Weibull parameters is generally done graphically by plotting the curve :

$$
\log \operatorname{Ln}\left(\frac{1}{1-P_{i}}\right)=f\left(\log x_{i}\right) .
$$

In these coordinates the function appears as a straight line, the parameters of which may be obtained via least square fitting.

Some examples of this type of plotting are shown in figure 7 for different geometries of thin films between two electrodes [7] ; note the high sensitivity of this distribution with the configuration.

If the surface voltage is taken as the random variable, (3) and (4) may be written :

$$
\begin{gathered}
F(V)=1-\exp \left[-\left(\frac{V_{\mathrm{s}}-V_{0}}{V_{\mathrm{c}}-V_{0}}\right)^{\mathrm{b}}\right] \\
Y(V)=\log \operatorname{Ln}\left(\frac{1}{1-F(V)}\right) \\
=b \log \left(V_{\mathrm{s}}-V_{0}\right)-b \log \left(V_{\mathrm{c}}-V_{0}\right) .
\end{gathered}
$$

Where the voltage the breakdown occurs we measure, along with the surface voltage, parameter $A$ which may be for example :

$$
\begin{array}{ll}
\text { peak current } & I_{\mathrm{p}} \\
\text { current rise time } & T_{\mathrm{m}} \\
\text { neutralized charge } & Q \\
\text { velocity } & W, \text { etc... }
\end{array}
$$

This parameter will obey a probability function ; if we plot the Weibull function for the parameter $A\left(V_{\mathrm{s}}-V_{0}\right)$ :

$$
Y(A)=F[\log (A)]
$$

generally it will not be a straight line in the coordinate $\left(Y(A), \log V_{\mathrm{s}}\right)$, except the case where :

$$
A\left(V_{\mathrm{s}}-V_{0}\right)=\alpha\left(V_{\mathrm{s}}-V_{0}\right)^{\gamma} \text {. }
$$

By using (5) and (6) relation (7) becomes :

or

$$
Y(A)=b \log \left(V_{\mathrm{s}}-V_{0}\right)+C^{\prime},
$$

$$
Y(A)=b \gamma^{-1} \log A+C^{\prime \prime} .
$$

We obtain a straight line in both coordinates $\left(Y(A), \log V_{\mathrm{s}}\right)$ and $[Y(A), \log (A)]$.

The relation (8) is identical to (2) for propagative discharge velocity at atmospheric pressure (the positive case is obtained with $\gamma<1$ ) [5].

By analogy we assume such a power law (with any $\gamma$ ) is obtained for the velocity of a linear discharge initiated at a value $V_{\mathrm{s}}$ of the potential. 


\section{Experimental checking.}

Our analysis is supported by the experimental results of Balmain [8]. The main features of the experiments were the following: the material is irradiated through a narrow aperture $(5 \mathrm{~mm})$ with a $20 \mathrm{keV}$ energy electron beam with $10 \mathrm{nA} / \mathrm{cm}^{2}$ of current density. The discharge initiated at a pinhole edge is a linear one ; the values of the velocity are determined from the transit time between two optical fibers, $3 \mathrm{~cm}$ distant. Such an experimental configuration may be called " a simple configuration " for which the discharge process is well identified. Results are displayed as the number of occurrence of discharges having a velocity $W_{i}$ (Fig. 8).

We can easily deduce from this the probability $P_{i}$, as the mean rank estimate $i / n+1, n$ being the total number of discharges considered as random independent samples.

By plotting $\log \left[-\operatorname{Ln}\left(1-P_{i}\right)\right]$ versus $\log W_{i}$ we readily obtained a straight line as can be seen in figure 9.

For the three cases studied by Balmain :

Teflon $60 \mu \mathrm{m}$, adjustment coefficient $\left({ }^{*}\right) 0.996$

Teflon $125 \mu \mathrm{m}$, adjustment coefficient 0.993

Mylar $75 \mu \mathrm{m}$, adjustment coefficient 0.897 .

More than $82 \%$ of the discharges had been taken into account leading to a probability higher than $10 \%$. We note that the dispersion range of the velocity between 10 and $90 \%$ of probability is nearly of the same order than dispersion range of the electrical strength measurements.

Naturally the conclusions arising from this result cannot be different from those of Balmain : both Teflon sample have a similar behaviour with no marked dependence on thickness which is not really surprising and a different distribution for Mylar which may be attributed to the different nature of materials. The distribution parameters values are indicated below :

$\begin{array}{lccc} & W_{\mathrm{c}} & (\mathrm{m} / \mathrm{s}) \times 10^{6} & b \\ \text { Teflon 60 } & & 0.82 & 5.17 \\ \text { Teflon 125 } & & 0.76 & 7.60 \\ \text { Mylar 75 } & & 1.20 & 3.12\end{array}$

The characteristic values of the velocity are not significantly different from the mean values given by Balmain from a Gaussian point of view (resp. 0.75, $\left.0.72,1.16 \times 10^{6} \mathrm{~m} / \mathrm{s}\right)$.

(*) The adjustment coefficient is defined in the case of a linear regression by the following relation :

$$
r^{2}=\frac{\left[\Sigma_{x_{i} y_{i}}-\frac{\Sigma_{x_{i} y_{i}}}{n}\right]^{2}}{\left[\Sigma_{x_{i}^{2}}-\frac{\left(\Sigma_{x_{i}}\right)^{2}}{\left[\Sigma_{y_{i}}-\frac{\left[\Sigma_{y_{i}}\right]^{2}}{n}\right]}\right.}
$$

with $x_{i}=\log w_{i}$ and $y_{i}=\log \left[-\operatorname{Ln}\left(1-P_{i}\right)\right]$.

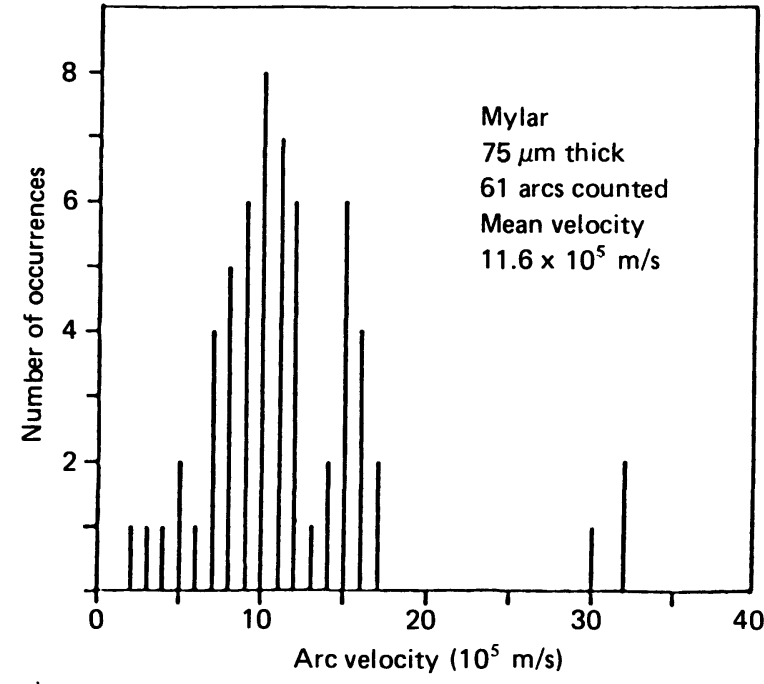

a)

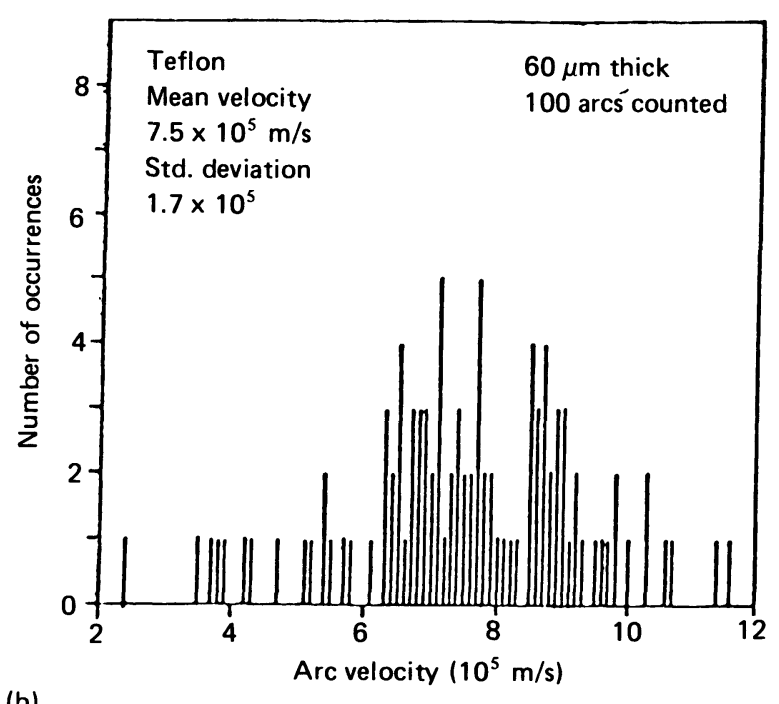

(b)

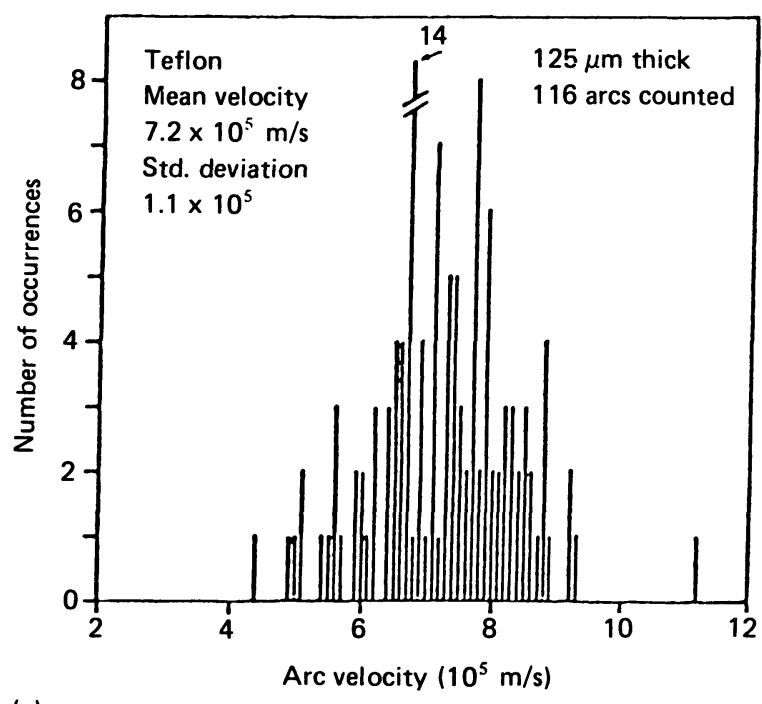

Fig. 8. - Distribution of measured linear discharges velocities on e-irradiated material. (a) Mylar $75 \mu \mathrm{m}$; (b) Teflon $60 \mu \mathrm{m}$; (c) Teflon $125 \mu \mathrm{m}$. From K. G. Balmain et al. [8]. 


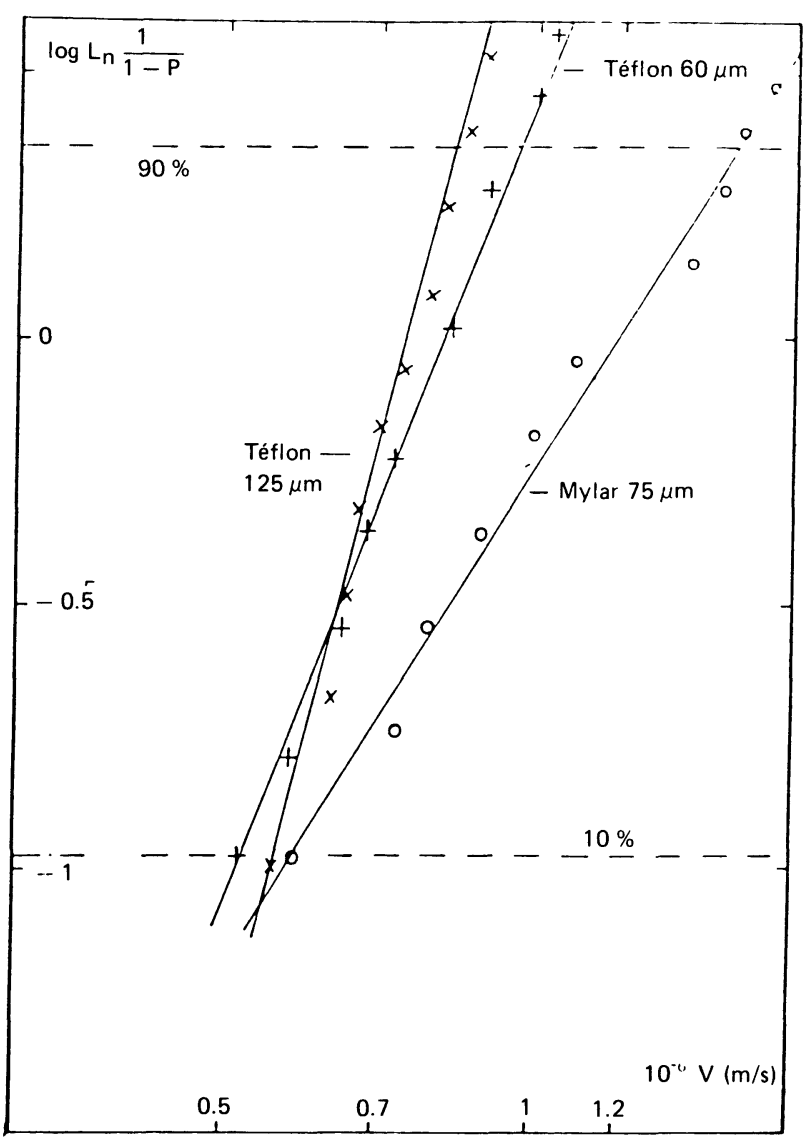

Fig. 9. - Weibull plots of linear discharge velocity deduced from Balmain et al. results [8].

In the absence of potential measurements, it is difficult to go further into the physical hypothesis.

We recall here the basic assumptions we made :

- the process leading to discharge is similar to that leading to dielectric breakdown,

- the velocity is a power law versus the surface potential.

These results are certainly not sufficient to confirm them ; but they do not infirm it and it is worth looking for a more accurate reality of such a law. This is one of our experimental aims.

\section{Conclusion.}

When dielectric properties are concerned we assume that discharges are initiated by mechanisms similar to those that lead to classical dielectric breakdown, although the voltage threshold may be different due to geometry or charging processes. Hence the appearance of a discharge may obey a statistical law similar to the Weibull law ; it may be this law itself (linear in log-log coordinate) or one presenting a slight departure from it. This law will be true for a specific irradiation condition defined as a set of parameters, as for example :

- a given energy beam and current density (that will govern temporal evolution of the potential and its final value),

- a geometrical configuration for one type of material.

To avoid superimposing the randomness of discharge onset on problems due to its complex spatiotemporal structure in the case of uniform irradiation, we will only treat linear discharge at first.

The significant parameters of this type of discharge, such as peak current or propagation velocity, are measurable during consecutive discharges and their law of probability established. If this law and the onset potential are known, it is possible to deduce the relationship between the two quantities. This is what we have set out to demonstrate by applying this method of reasoning to the linear discharge propagation velocity measurements obtained by Balmain et al. [8]. The probability laws for velocity and potential are compatible with a Weibull-type distribution function if we assume a law for velocity of the type $\left(V_{\mathrm{s}}-V_{0}\right)^{\gamma}$, law assumed by analogy with surface discharge at atmospheric pressure.

Determination of these laws of probability can be undertaken in laboratory using simple configurations for which the discharge process has been properly identified, i.e., we have set the following objectives :

(1) Verify the existence of such a statistical law and establish this law for some of the major parameters and first of all surface voltage. The sensitivity of the Weibull factors ( $b$ and $x_{\mathrm{c}}$ ) to the irradiation condition and to the type of material may be significant in evaluating actual risks.

(2) Determine the relationship between current parameters (intensity, rise time) or propagation velocity and the surface potential. By comparison of similar laws derived at atmospheric pressure, pertinent data may be deduced on the physical process leading to breakdown or driving of the discharge.

\section{References}

[1] Purvis, C. K., Garret, H. B., Whittlesey, A. C., STEVENS, N. J., Design Guidelines for Assessing and Controlling Spacecraft Charging Effects, NASA T. P. 2361 sept. (1984).

[2] NASA Charging Analyser Program (NASCAP). See for example: KATZ, I., The capabilities of the NASA Charging Analyser Program, Spacecraft
Charging Technology, 1978, NASA CP 2071 (1979) 101.

KATZ, I., NASCAP, a 3D Charging Analyzer Program for complex spacecraft, IEEE Trans. Nucl. Sci. NS 24 (1977) 2276.

SANDERS, N. L., INOUYE, G., Spacecraft Charging Technology, 1980, NASA CP 2182 (1981) 684. 
[3] Bondiou, A., Labaune, G., Marque, J. P., Electromagnetic radiation associated to the breakdown of air at atmospheric pressure, 10th International Aerospace and Ground Conference on Lightning and Static Electricity (Paris) 1985.

[4] Bondiou, A., Thèse de Docteur-Ingénieur, Université d'Orsay $n^{\circ} 672$ (1984).

[5] LARIGAldiE, S., (a) High current discharge propagation analysis. Application to the lightning leader, 10th International Aerospace and Ground Conference on Lightning and Static Electricity (Paris) 1985. (b) Thèse d'Etat, Université d'Orsay n 3107 (1985).
[6] Hill, R. M., Dissado, L. A., Examination of the statistics of dielectric breakdown, J. Phys. C 16 (1983) 4447.

[7] Seanor, D. A., Electrical properties of Polymers, Ac. Press. (1982).

[8] Balmain, K. G., Gossland, M., Reeves, R. D., Kuller, W. G., Optical measurement of the velocity of dielectric surface arc, IEEE Trans. Nucl. Sci. NS 29 nº (1982) 1615. 